\title{
Stock Returns and Market Making with
}

\section{Inventory}

\author{
Seyoung Park \\ Department of Industrial and Management Eng., POSTECH \\ Bong-Gyu Jang* \\ Department of Industrial and Management Eng., POSTECH
}

(Received: April 23, 2012 / Revised: June 8, 2012 / Accepted: June 11, 2012)

\begin{abstract}
We study optimal trading strategy of a market maker with stock inventory. Following Avellaneda and Stoikov (2008), we assume the stock price follows a normal distribution. However, we take a constant expected rate of the stock return and assume that the stock volatility is an inverse function of the stock price level. We show that the optimal bid-ask spread of the market maker is wider for a higher expected rate of stock returns.
\end{abstract}

Keywords: Market Maker, Bid-Ask Spread, Stock Return, Stock Inventory, Dynamic Programming

* Corresponding Author, E-mail: bonggyujang@postech.ac.kr

\section{INTRODUCTION}

The study of optimal behaviors of dealers has been regarded as an important research subject, so that there exist lots of literature in this area. ${ }^{1)}$ Among them, Ho and Stoll (1981) examine the optimal behaviors of a single dealer with stock inventory. They employ the dynamic programming approach to find the maximal expected utility of the dealer at the terminal time and determine her optimal bid and ask strategies. Following them, Avellaneda and Stoikov (2008) suggest the optimal bid and ask strategies of an agent with constant absolute risk aversion (CARA) type utility with respect to her terminal wealth.

The objective of this paper is to derive the optimal trading strategies of a dealer who plays market maker's role with a stock inventory. We assume that the dealer has monopolistic power in trading the stock and is riskaverse, more specifically she has a CARA type utility with respect to her terminal wealth. Actually, lots of

1) For example, Biais et al. (2010), Stoll (2003), and O'Hara (1997) provide the reader with an extensive survey in this area. articles on existing literature assume that dealers are risk-neutral and stock markets are perfectly competitive (e.g., Copeland and Galai, 1983; Kyle, 1985; Glosten and Milgrom, 1985). Lyons (1995) and others, however, find that dealers could be very risk-averse, and we take this result as an assumption in our paper. Moreover, Christie and Schultz (1994), Chen and Ritter (2000), and Biais et al. (2010) show that financial markets are not perfectly competitive. Thus, the assumption of a monopolistic dealer in a stock market is not Platonic.

Our paper is considered as an extension of the paper by Avellaneda and Stoikov (2008), but we employ asset price processes different from them. Avellaneda and Stoikov (2008) assume that the stock price process follows an arithmetic Brownian motion without any drift and the risk-free rate is zero. The stock price process in our paper is also assumed to be an arithmetic Brownian motion but we take a constant expected rate of the stock return and assume that the stock volatility is an inverse function of the stock price level, which could reflect the so-called leverage effect. Further, the risk-free rate is assumed to be constant. The difference leads us to understand more about the effect of the expected rate of stock returns on the mid or long term market making. 


\section{THE MODEL}

We assume there is a filtered probability space $\left(\Omega, \mathrm{P}, \mathrm{F},\left\{\mathrm{F}_{\mathrm{t}}\right\}\right)$ and the filtration $\left\{\mathrm{F}_{\mathrm{t}}\right\}_{\mathrm{t} \geq 0}$ satisfying the usual conditions. Also we let $\mathrm{W}_{\mathrm{t}}$ be a $\left\{\mathrm{F}_{\mathrm{t}}\right\}$-adapted standard one-dimensional Brownian motion.

We consider a monopolistic agent of a stock. She is willing to trade through limit orders to make profits. We assume that there are two assets that the agent can trade; a money market instrument (or a bond) and the stock. Let $r$ be the return from the bond, that is, the risk-free interest rate. The stock price process $\mathrm{y}_{\mathrm{t}}$ is evolved by

$$
d y_{t}=\mu y_{t} d t+\sigma w_{t},
$$

where $\mu>r, \sigma$ are positive constants. For this case, the dollar amount of the agent's investment in the bond at time $\mathrm{y}_{\mathrm{t}}$ is represented as

$$
\mathrm{dx}_{\mathrm{t}}=\mathrm{rx}_{\mathrm{t}} \mathrm{dt}-\left(\mathrm{y}_{\mathrm{t}}-\mathrm{B}_{\mathrm{t}}\right) \mathrm{dL}_{\mathrm{t}}+\left(\mathrm{y}_{\mathrm{t}}+\mathrm{A}_{\mathrm{t}}\right) \mathrm{dU_{ \textrm {t } }},
$$

where $B_{t}\left(A_{t}\right)$ denotes the distance between the stock price $y_{t}$ and the agent's bid price (ask price, respectively). Thus they satisfy

$$
\left\{\begin{array}{l}
\mathrm{B}_{\mathrm{t}}=\mathrm{y}_{\mathrm{t}}-\mathrm{BP}_{\mathrm{t}}, \\
\mathrm{A}_{\mathrm{t}}=\mathrm{AP}_{\mathrm{t}}-\mathrm{y}_{\mathrm{t}},
\end{array}\right.
$$

where $\mathrm{BP}_{t}$ and $\mathrm{AP}_{t}$ denote the bid and ask prices of the agent at time $t . \mathrm{dL}_{t}\left(\mathrm{dU}_{\mathrm{t}}\right)$ represents the number of shares of the stock bought (sold, respectively) by the agent through limit orders at time $t$, thus, $\mathrm{L}_{\mathrm{t}}\left(\mathrm{U}_{\mathrm{t}}\right)$ can be thought of as the cumulative shares purchased (sold, respectively). satisfy

More specifically, we define them as the processes

$$
\begin{aligned}
& \mathrm{dL}_{\mathrm{t}}=\left\{\begin{array}{lr}
1 & \text { with probability } \mathrm{I}\left(\mathrm{B}_{\mathrm{t}}\right) \mathrm{dt} \\
0 & \text { with probability } 1-\mathrm{I}\left(\mathrm{B}_{\mathrm{t}}\right) \mathrm{dt}
\end{array}\right. \\
& \mathrm{dU}_{\mathrm{t}}=\left\{\begin{array}{l}
1 \quad \text { with probability } \mathrm{I}\left(\mathrm{A}_{\mathrm{t}}\right) \mathrm{dt} \\
0 \text { with probability } 1-\mathrm{I}\left(\mathrm{A}_{\mathrm{t}}\right) \mathrm{dt}
\end{array}\right.
\end{aligned}
$$

where $I\left(B_{t}\right)$ and $I\left(A_{t}\right)$ are arrival intensities of market sell and buy orders, and dependent on the agent's bid and ask distances. Following Avellaneda and Stoikov (2008), we assume the symmetric order arrival intensities of the following form:

$$
\begin{aligned}
I\left(A_{t}\right) & =C \exp \left(-k A_{t}\right), \\
I\left(B_{t}\right) & =\operatorname{Cexp}\left(-k B_{t}\right),
\end{aligned}
$$

where $\mathrm{C}$ and $\mathrm{k}$ are positive constants.

Notice that we are assuming the stock price follows a normal distribution (see (1)) and, thus, the expected rate of the stock return is constant and the stock volatility is an inverse function of the stock price. Different from our model, Avellaneda and Stoikov (2008) assume the stock price process is an arithmetic Brownian motion without any drift, and also assume the zero risk-free rate. Seemingly, their model focuses on daily (or extremely short term) bidding and asking strategies of a market maker, while our model could be used in both short-term and long-term market making.

At last, we know that the change in the number of the holding stocks (or stock inventory) of the agent should satisfy

$$
\mathrm{dq}_{\mathrm{t}}=\mathrm{dL}_{\mathrm{t}}-\mathrm{dU}_{\mathrm{t}} \text {. }
$$

\section{THE OPTIMAL BID-ASK SPREAD}

The agent's objective is to find the value function of

$$
\mathrm{V}(\mathrm{x}, \mathrm{y}, \mathrm{q}, \mathrm{t})=\max _{\mathrm{A}_{\mathrm{t}} \mathrm{B}_{\mathrm{t}}} \mathrm{E}\left[-\exp \left(-\gamma\left(\mathrm{x}_{\mathrm{T}}+\mathrm{q}_{\mathrm{T}} \mathrm{y}_{\mathrm{T}}\right)\right) \mid \mathrm{F}_{\mathrm{t}}\right]
$$

where $\mathrm{x}$ is the initial wealth invested in a bond, $\mathrm{y}$ is the initial stock price, and $\mathrm{q}$ is the initial stock inventory of the agent. Utilizing the dynamic programming principle, we can get the Hamilton-Jacobi-Bellman (HJB) equation for the value function $\mathrm{V}$ :

$$
\left\{\begin{array}{l}
\mathrm{V}_{\mathrm{t}}+\mathrm{rxV}_{\mathrm{x}}+\mu \mathrm{y} \mathrm{V}_{\mathrm{y}}+\frac{1}{2} \sigma^{2} \mathrm{~V}_{\mathrm{yy}} \\
+\max _{\mathrm{B}_{\mathrm{t}}} \mathrm{I}\left(\mathrm{B}_{\mathrm{t}}\right)\left[\mathrm{V}\left(\mathrm{x}-\mathrm{y}+\mathrm{B}_{\mathrm{t}}, \mathrm{y}, \mathrm{q}+1, \mathrm{t}\right)-\mathrm{V}(\mathrm{x}, \mathrm{y}, \mathrm{q}, \mathrm{t})\right] \\
+\max _{\mathrm{A}_{\mathrm{t}}} \mathrm{I}\left(\mathrm{A}_{\mathrm{t}}\right)\left[\mathrm{V}\left(\mathrm{x}+\mathrm{y}+\mathrm{A}_{\mathrm{t}}, \mathrm{y}, \mathrm{q}-1, \mathrm{t}\right)-\mathrm{V}(\mathrm{x}, \mathrm{y}, \mathrm{q}, \mathrm{t})\right]=0 \\
\mathrm{~V}(\mathrm{x}, \mathrm{y}, \mathrm{q}, \mathrm{t})=-\exp (-\gamma(\mathrm{x}+\mathrm{qy}))
\end{array}\right.
$$

where $\mathrm{V}_{\mathrm{t}}=\frac{\partial \mathrm{V}}{\partial \mathrm{t}}, \mathrm{V}_{\mathrm{x}}=\frac{\partial \mathrm{V}}{\partial \mathrm{x}}, \mathrm{V}_{\mathrm{y}}=\frac{\partial \mathrm{V}}{\partial \mathrm{y}}$ and $\mathrm{V}_{\mathrm{yy}}=\frac{\partial^{2} \mathrm{~V}}{\partial \mathrm{y}^{2}}$.

We conjecture that the value function has the following form:

$$
\mathrm{V}(\mathrm{x}, \mathrm{y}, \mathrm{q}, \mathrm{t})=-\exp \left(-\gamma \mathrm{xe}^{\mathrm{r}(\mathrm{T}-\mathrm{t})}-\mathrm{u}(\mathrm{z}, \mathrm{q}, \mathrm{t})\right)
$$

for $\mathrm{z}=\gamma \mathrm{ye}^{\mathrm{r}(\mathrm{T}-\mathrm{t})}$. By using this change of variable, the HJB Equation (2) could be rewritten as

$$
\left\{\begin{array}{l}
\mathrm{u}_{\mathrm{t}}+(\mu-\mathrm{r}) \mathrm{zu}_{\mathrm{z}}+\frac{1}{2} \sigma^{2} \mathrm{r}^{2} \mathrm{e}^{2 \mathrm{r}(\mathrm{T}-\mathrm{t})}\left(\mathrm{u}_{\mathrm{zz}}-\mathrm{u}_{\mathrm{z}}^{2}\right) \\
+\max _{\mathrm{B}_{\mathrm{t}}} \mathrm{I}\left(\mathrm{B}_{\mathrm{t}}\right)\left[1-\exp \left\{-\gamma\left(-\mathrm{z}+\mathrm{B}_{\mathrm{t}} \mathrm{e}^{\mathrm{r}(\mathrm{T}-\mathrm{t})}\right)\right.\right. \\
-(\mathrm{u}(\mathrm{z}, \mathrm{q}+1), \mathrm{t})-\mathrm{u}(\mathrm{z}, \mathrm{q}, \mathrm{t}))\}] \\
+\max _{\mathrm{A}_{\mathrm{t}}} \mathrm{I}\left(\mathrm{A}_{\mathrm{t}}\right)\left[1-\exp \left\{-\gamma\left(\mathrm{z}+\mathrm{A}_{\mathrm{t}} \mathrm{e}^{\mathrm{r}(\mathrm{T}-\mathrm{t})}\right)\right.\right. \\
+(\mathrm{u}(\mathrm{z}, \mathrm{q}-1), \mathrm{t})-\mathrm{u}(\mathrm{z}, \mathrm{q}, \mathrm{t}))\}]=0 \\
\mathrm{u}(\mathrm{z}, \mathrm{q}, \mathrm{T})=\mathrm{qz} .
\end{array}\right.
$$

Define $R_{b}(z, q, t)$ and $R_{a}(z, q, t)$ by

$$
\left\{\begin{array}{l}
\mathrm{R}_{\mathrm{b}}(\mathrm{z}, \mathrm{q}, \mathrm{t})=\mathrm{u}(\mathrm{z}, \mathrm{q}+1, \mathrm{t})-\mathrm{u}(\mathrm{z}, \mathrm{q}, \mathrm{t}) \\
\mathrm{R}_{\mathrm{a}}(\mathrm{z}, \mathrm{q}, \mathrm{t})=\mathrm{u}(\mathrm{z}, \mathrm{q}, \mathrm{t})-\mathrm{u}(\mathrm{z}, \mathrm{q}-1, \mathrm{t})
\end{array}\right.
$$


According to Ho and Stoll (1981) and Avellaneda and Stoikov (2008), they are called reservation bid and ask prices. The first-order condition (FOC) with respect to $\mathrm{B}_{\mathrm{t}}$ yields

$$
\begin{aligned}
& \gamma \mathrm{z}-\mathrm{R}_{\mathrm{b}}(\mathrm{z}, \mathrm{q}, \mathrm{t}) \\
& \quad=\gamma \mathrm{e}^{\mathrm{r}(\mathrm{T}-\mathrm{t})} \mathrm{B}_{\mathrm{t}}-\ln \left[1-\gamma \mathrm{e}^{\mathrm{r}(\mathrm{T}-\mathrm{t})} \mathrm{I}\left(\mathrm{B}_{\mathrm{t}}\right) / \frac{\partial \mathrm{I}\left(\mathrm{B}_{\mathrm{t}}\right)}{\partial \mathrm{B}_{\mathrm{t}}}\right],
\end{aligned}
$$

and the $\mathrm{FOC}$ with respect to $\mathrm{A}_{t}$ yields

$$
\begin{aligned}
\gamma \mathrm{z}- & \mathrm{R}_{\mathrm{b}}(\mathrm{z}, \mathrm{q}, \mathrm{t}) \\
& =\gamma \mathrm{e}^{\mathrm{r}(\mathrm{T}-\mathrm{t})} \mathrm{A}_{\mathrm{t}}-\ln \left[1-\gamma \mathrm{e}^{\mathrm{r}(\mathrm{T}-\mathrm{t})} \mathrm{I}\left(\mathrm{A}_{\mathrm{t}}\right) / \frac{\partial \mathrm{I}\left(\mathrm{A}_{\mathrm{t}}\right)}{\partial \mathrm{A}_{\mathrm{t}}}\right],
\end{aligned}
$$

Plugging (4) and (5) into (3) and exploiting the linear approximation ${ }^{2)}$ of

$$
\exp \left(-\mathrm{kA}_{\mathrm{t}}\right)+\exp \left(-\mathrm{kB}_{\mathrm{t}}\right) \approx 2-\mathrm{k}\left(\mathrm{A}_{\mathrm{t}}+\mathrm{B}_{\mathrm{t}}\right)
$$

the HJB equation (3) has a new form:

$$
\left\{\begin{array}{l}
\mathrm{u}_{\mathrm{t}}+(\mu-\mathrm{r}) \mathrm{zu}_{\mathrm{z}}+\frac{1}{2} \sigma^{2} \gamma^{2} \mathrm{e}^{2 \mathrm{r}(\mathrm{T}-\mathrm{t})}\left(\mathrm{u}_{\mathrm{zz}}-\mathrm{u}_{\mathrm{z}}^{2}\right) \\
+\frac{\mathrm{C} \gamma \mathrm{e}^{\mathrm{r}(\mathrm{T}-\mathrm{t})}}{\mathrm{k}+\gamma \mathrm{e}^{\mathrm{r}(\mathrm{T}-\mathrm{t})}}\left(2-\mathrm{k}\left(\mathrm{A}_{\mathrm{t}}+\mathrm{B}_{\mathrm{t}}\right)\right)=0, \\
\mathrm{u}(\mathrm{z}, \mathrm{q}, \mathrm{T})=\mathrm{qz},
\end{array}\right.
$$

The following theorem describes the optimal bidding and asking strategies of the agent in our model.

THEOREM 3.1: The optimal bid-ask spread should be

$$
\begin{aligned}
\mathrm{A}_{\mathrm{t}}+\mathrm{B}_{\mathrm{t}}= & \frac{\sigma^{2} \gamma}{2 \mu} \mathrm{e}^{-\mathrm{r}(\mathrm{T}-\mathrm{t})}\left(\mathrm{e}^{2 \mu(\mathrm{T}-\mathrm{t})}-1\right) \\
& +\frac{2}{\gamma} \mathrm{e}^{-\mathrm{r}(\mathrm{T}-\mathrm{t})} \ln \left(1+\frac{\gamma}{\mathrm{k}} \mathrm{e}^{\mathrm{r}(\mathrm{T}-\mathrm{t})}\right)
\end{aligned}
$$

Proof: We conjecture the solution of equation (6) is the following: for appropriate functions $u_{0}, u_{1}$ and $u_{2}$,

$$
u(z, q, t)=u_{0}(z, t)+u_{1}(z, t) q+u_{2}(z, t) q^{2}
$$

Then, the reservation bid and ask prices are

$\mathrm{R}_{\mathrm{b}}(\mathrm{z}, \mathrm{q}, \mathrm{t})=\mathrm{u}(\mathrm{z}, \mathrm{q}+1, \mathrm{t})-\mathrm{u}(\mathrm{z}, \mathrm{q}, \mathrm{t})=\mathrm{u}_{1}+(2 \mathrm{q}+1) \mathrm{u}_{2}$, $\mathrm{R}_{\mathrm{a}}(\mathrm{z}, \mathrm{q}, \mathrm{t})=\mathrm{u}(\mathrm{z}, \mathrm{q}, \mathrm{t})-\mathrm{u}(\mathrm{z}, \mathrm{q}-1, \mathrm{t})=\mathrm{u}_{1}+(2 \mathrm{q}-1) \mathrm{u}_{2}$,

The bid-ask spread, $A_{t}+B_{t}$, is given by

$$
\mathrm{A}_{\mathrm{t}}+\mathrm{B}_{\mathrm{t}}=-\frac{2}{\gamma} \mathrm{e}^{-\mathrm{r}(\mathrm{T}-\mathrm{t})} \mathrm{u}_{2}+\frac{2}{\gamma} \mathrm{e}^{-\mathrm{r}(\mathrm{T}-\mathrm{t})} \ln \left(1+\frac{\gamma}{\mathrm{k}} \mathrm{e}^{\mathrm{r}(\mathrm{T}-\mathrm{t})}\right) .
$$

2) Avellaneda and Stoikov (2008) also exploit this kind of linear approximation.
Plugging (8) into the equation in (6) and utilizing the fact that the coefficient terms of each orders of q should be zero after grouping it according to each order of $\mathrm{q}$, we can get the following equations:

$$
\begin{aligned}
& \left\{\begin{array}{l}
\left(\mathrm{u}_{1}\right)_{\mathrm{t}}+(\mu-\mathrm{r}) \mathrm{z}\left(\mathrm{u}_{1}\right)_{\mathrm{z}} \\
+\frac{1}{2} \sigma^{2} \gamma^{2} \mathrm{e}^{2 \mathrm{r}(\mathrm{T}-\mathrm{t})}\left\{\left(\mathrm{u}_{1}\right)_{\mathrm{zz}}-2\left(\mathrm{u}_{0}\right) \mathrm{z}\left(\mathrm{u}_{1}\right)_{\mathrm{z}}\right\}=0, \\
\mathrm{u}_{1}(\mathrm{z}, \mathrm{T})=\mathrm{z},
\end{array}\right. \\
& \left\{\begin{array}{l}
\left(\mathrm{u}_{2}\right)_{\mathrm{t}}+(\mu-\mathrm{r}) \mathrm{z}\left(\mathrm{u}_{2}\right)_{\mathrm{z}} \\
+\frac{1}{2} \sigma^{2} \gamma^{2} \mathrm{e}^{2 \mathrm{r}(\mathrm{T}-\mathrm{t})}\left[\left(\mathrm{u}_{2}\right)_{\mathrm{zz}}-\left\{\left(u_{1}\right)_{\mathrm{z}}^{2}+2\left(u_{0}\right)_{\mathrm{z}}\left(u_{2}\right)_{\mathrm{z}}\right\}\right]=0, \\
\mathrm{u}_{2}(\mathrm{z}, \mathrm{T})=0,
\end{array}\right.
\end{aligned}
$$

and

$$
\left\{\begin{array}{l}
\left(\mathrm{u}_{0}\right)_{\mathrm{t}}+(\mu-\mathrm{r}) \mathrm{z}\left(\mathrm{u}_{0}\right)_{\mathrm{z}}+\frac{1}{2} \sigma^{2} \gamma^{2} \mathrm{e}^{2 \mathrm{r}(\mathrm{T}-\mathrm{t})}\left\{\left(\mathrm{u}_{0}\right)_{\mathrm{zz}}-\left(\mathrm{u}_{0}\right)_{\mathrm{z}}^{2}\right\} \\
+\frac{\mathrm{C} \gamma \mathrm{e}^{\mathrm{r}(\mathrm{T}-\mathrm{t})}}{\mathrm{k}+\gamma \mathrm{e}^{\mathrm{r}(\mathrm{T}-\mathrm{t})}}\left[2-\mathrm{k}\left\{-2 \mathrm{u}_{2}+\frac{2}{\gamma} \ln \left(1+\frac{\gamma}{\mathrm{k}}\right)\right\}\right]=0, \\
\mathrm{u}_{0}(\mathrm{z}, \mathrm{T})=0,
\end{array}\right.
$$

Then,

$$
\begin{aligned}
& \mathrm{u}_{1}(\mathrm{z}, \mathrm{t})=\mathrm{ze}^{(\mu-\mathrm{r})(\mathrm{T}-\mathrm{t})}, \\
& \mathrm{u}_{2}(\mathrm{z}, \mathrm{t})=\frac{1}{4 \mu} \sigma^{2} \gamma^{2}\left(1-\mathrm{e}^{2 \mu(\mathrm{T}-\mathrm{t})}\right)
\end{aligned}
$$

and $\mathrm{u}_{0}(\mathrm{z}, \mathrm{t})$ is the function which is independent of $\mathrm{z}$ variable and satisfies the last equation above. true.

(9) and the solution $u_{2}$ above make the equality (7)

Theorem 3.1 says that the optimal bid-ask spread could be affected by both the risk-free interest rate and the expected rate of return of the stock. Under the zero interest rate market situation, the second-order Taylor series expansion of the right hand side of (7) with respect to $\mu$ should be

$$
\sigma^{2} \gamma(\mathrm{T}-\mathrm{t})+\frac{2}{\gamma} \ln \left(1+\frac{\gamma}{\mathrm{k}}\right)+\sigma^{2} \mu \gamma(\mathrm{T}-\mathrm{t})^{2}
$$

Notice that the sum of the first two terms is equivalent to the optimal bid-ask spread suggested by the Avellaneda and Stoikov (2008). The third term tells us that in a high stock volatility regime market makers with a high risk aversion and a long investment horizon might be sensitive on the change of stock return. As a matter of fact, they have wider bid-ask spreads when bigger stock returns are expected. Figure 1 shows the optimal bid-ask spreads as a function of time variable $t$ for several $\mu$ 's, and we find non-negligible gaps between them for a longer trading time $(\mathrm{T}-\mathrm{t})$ of the agent. 


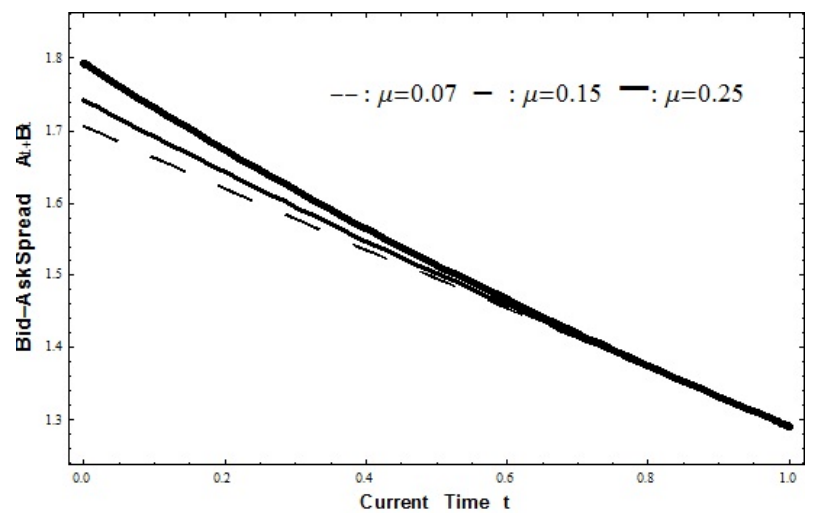

Figure 1. Optimal Bid-Ask Spread As a Function of Current Time t. $\mathrm{T}=1, \mathrm{r}=0.03, \sigma=2, \gamma=0.1$, $\mathrm{k}=1.5$, and $\mathrm{C}=140$ are used as parameter values

\section{CONCLUSION}

This paper examines the optimal bid-ask spreads of a monopolistic market maker with stock inventory, and we provide a closed-from formula for her optimal bidding and asking strategies. The result tells us that considering the expected rate of stock return might be important for market makers with a long-term investment horizon.

\section{ACKNOWLEDGEMENT}

This research was supported by Basic Science Research Program through the National Research Foundation of Korea (NRF) funded by the Ministry of Education, Science and Technology (No. 2012-0003789) and the POSTECH Basic Science Research Institute Grant (No. 4.0006572.01).

\section{REFERENCES}

Avellaneda, M. and S. Stoikov, "High-Frequency Trading in a Limit Order Book," Quantitative Finance 8 3 (2008), 217-224.

Biais, B., C. Bisière, and C. Spatt, "Imperfect Competition in Financial Markets: An Empirical Study of Island and Nasdaq," Management Science 56, 12 (2010), 2237-2250.

Chen, H. and J. Ritter, "The Seven Percent Solution," Journal of Finance 55, 3 (2000), 1105-1131.

Christie, W. and P. Schultz, "Why do Nasdaq Market Makers Avoid Odd-Eighth Quotes?," Journal of Finance 49, 5 (1994), 1813-1840.

Copeland, T. E. and D. Galai, "Information Effects and the Bid-Ask Spread," Journal of Finance 38, 5 (1983), 1457-1469.

Glosten, L. R. and P. R. Milgrom, "Bid, Ask, and Transaction Prices in a Specialist Market with Heterogeneously Informed Traders," Journal of Financial Economics 14, 1 (1985), 71-100.

Ho, T. and H. R. Stoll, "Optimal Dealer Pricing under Transactions and Return Uncertainty," Journal of Financial Economics 9, 1 (1981), 47-73.

Kyle, A., "Continuous Auctions and Insider Trading," Econometrica 53, 6 (1985), 1315-1335.

Lyons, R. K., "Test of Microstructural Hypotheses in the Foreign Exchange Market," Journal of Financial Economics 39, 2/3 (1995), 321-351.

O'Hara, M., "Market Microstructure Theory," Bl-ackwell: Cambridge, 1997.

Stoll, H. R., "Market Microstructure," Handbook of the Economics of Finance (edited by Constantinides, G. M.), North Holland: Amsterdam, 2003. 